\title{
EAl Endorsed Transactions

\section{IoT-Q-Band: A low cost internet of things based wearable band to detect and track absconding COVID-19 quarantine subjects}

\author{
Vibhutesh Kumar Singh ${ }^{1}$, Himanshu Chandna ${ }^{2, *}$, Ashish Kumar $^{3}$, Sujeet Kumar ${ }^{4}$, Nidhi \\ Upadhyay $^{5}$, Kumar Utkarsh ${ }^{6}$ \\ ${ }^{1}$ Graduate Student Member, Institute of Electrical and Electronics Engineers (IEEE), Uttar Pradesh Section, India. \\ ${ }^{2}$ Mansa Ram Park, Uttam Nagar, New Delhi, India. \\ ${ }^{3}$ Saguna More, Danapur Cantt., Patna, Bihar, India. \\ ${ }^{4}$ New Layal Pur, Krishna Nagar, Delhi, India. \\ ${ }^{5}$ Circuit Uncle ${ }^{\mathrm{TM}}$, Uttam Nagar, New Delhi, India. \\ ${ }^{6}$ Associate Member, The British Computer Society (BCS), United Kingdom.
}

\section{Abstract}

The world health organization (WHO) has declared the novel coronavirus disease (COVID-19 or 2019-nCoV) outbreak a pandemic, and quarantines are playing a vital role in containing its spread. But globally, the defections of the quarantined subjects are raising serious concerns. If COVID-19 positive, the absconding quarantine subjects can infect more people, which makes their timely detection vital. As the literature suggests, a wearable makes a subject more compliant towards healthcare routines/restrictions; thus, in this work, we have designed an IoT based wearable quarantine band (IoT-Q-Band) to detect the absconding. While designing it, we kept in mind the cost, global supply chain disruption, and COVID-19 quarantine duration, which the WHO recommends. This wearable prototype, with the bundled mobile app, reports and tracks the absconding quarantine subjects in real-time. IoT-Q-Band is an economical solution that could benefit lowincome regions to prevent the spread of COVID-19.

\section{Received on 11 April 2020; accepted on 17 April 2020; published on 24 April 2020}

Keywords: wearable, quarantine band, coronavirus disease, nCov, COVID-19, demonstration, Internet of things, Smart devices, Demonstration, Experimentation, Proof-of-concept, Prototypes and demonstrators, Embedded systems

Copyright (C) 2020 V.K. Singh et al., licensed to EAI. This is an open access article distributed under the terms of the Creative Commons Attribution license (http://creativecommons.org/licenses/by/3.0/), which permits unlimited use, distribution and reproduction in any medium so long as the original work is properly cited.

doi:10.4108/eai.13-7-2018.163997

\section{Introduction}

According to the World Health Organization (WHO), a pandemic is "the worldwide spread of a new disease" [1]. Another descriptive definition of a pandemic says: "an epidemic occurring worldwide, or over a vast area, crossing international boundaries and usually affecting a large number of people" [2].

\footnotetext{
ऋ The authors encourage further optimizations/enhancements to the current state of the project. The associated data and files of this project will be made available at: https://github.com/circuituncle/ IoTQBand. IoT-Q-Band's demo video is available at: https: // youtu. be /Wx0_45u2ihI

*Corresponding author. Email: himanshu14144@iiitd.ac.in
}

On March 11, 2020, the WHO has marked the outbreak of novel coronavirus disease $(\mathrm{nCoV}$ or COVID-19 or SARS-CoV-2) a pandemic [3] [4] and as of April 21, 2020 5:00 PM Indian standard time, there has been more than 2.1 million confirmed infections, 135 thousand confirmed deaths and spread across 213 countries, areas or territories [5]. Various COVID-19 related research, including [6] [7] [8], mathematically modeled the number of infections with an exponential growth function (with reproduction number (R0) greater than 2). Thus an explosion of coronavirus infections may occur in real if the measures like quarantine and isolation of the infected or exposed persons are not applied. 


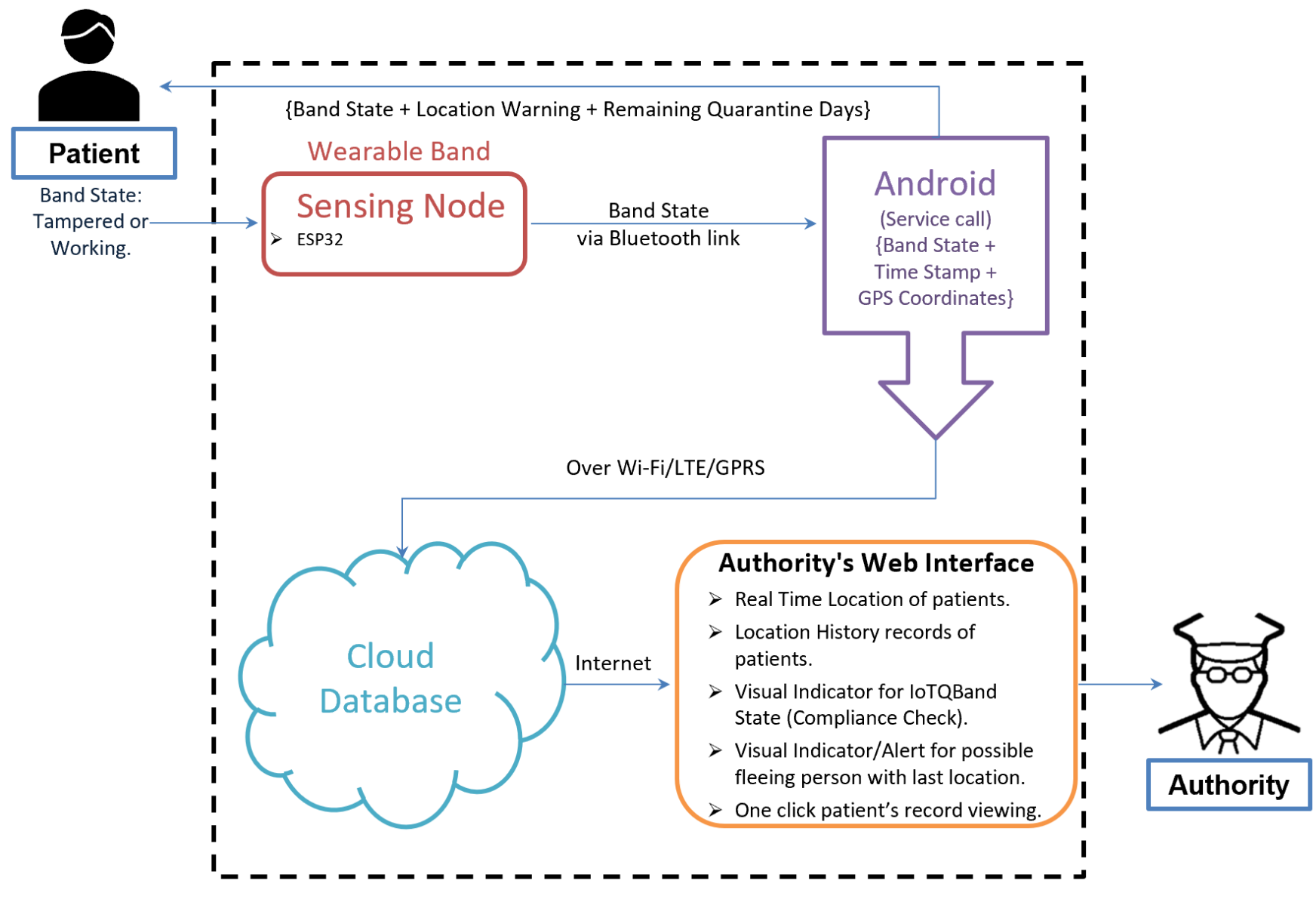

Figure 1. System architecture of the loT-Q-Band system.

To mitigate the growth of infections, quarantine (along with the isolation and social distancing) plays a pivotal role [9] which according to the WHO [10] is defined as, "the quarantine of persons is the restriction of activities of or the separation of persons who are not ill but who may be exposed to an infectious agent or disease, to monitor their symptoms and ensure the early detection of cases". Introducing quarantine measures early in a disease outbreak delay the disease outbreak and delay the peak of an epidemic in a country [10]. The success of the quarantine measures is primarily dependent on the subject's compliance, which is influenced by the sense of civic duty or the social responsibility of a person and varies over countries and cultures [11] [12]. During the COVID-19 outbreak, various reports emerge of people absconding from the quarantines and hospitals [13] [16].

The tracking of COVID-19 positive patients is carried out mostly through mobile applications, e.g., Aarogya Setu. As of April 21, 2020, Aarogya Setu works on the concept of crowdsourcing. As per this app's user reviews, the functionality of alerts to nearby users is limited, since it assumes that every person that has a smartphone have this application installed. The users have also shown concerns about the legitimacy of data entered in the app, suggesting a need for verifying or approving authority. Though the mobile app-based tracking seems inadequate, a visual indicator based tracking method (e.g., medical authorities stamping on the hands with a non-washable ink [21]), is most successful in detecting the absconding COVID19 quarantine subjects [22] [23]. But as in each case [22] [23], the absconding subjects were caught far away from their quarantine location, and reported through the common public; the timely alert to the authorities would have proved more worthy. Thus, to detect the absconding subjects on time, none of the two mentioned schemes seems to work effectively and somehow violates the privacy of subjects as well. Various healthcare studies, e.g., [17] - [20], suggests the use of wearable device make a patient more compliant to medical routines and restrictions; thus a wearable band would be a right solution for this case. Thus, we have designed a wearable band bundled with a mobile application, would detect and track the absconding quarantine subjects in real-time. This 


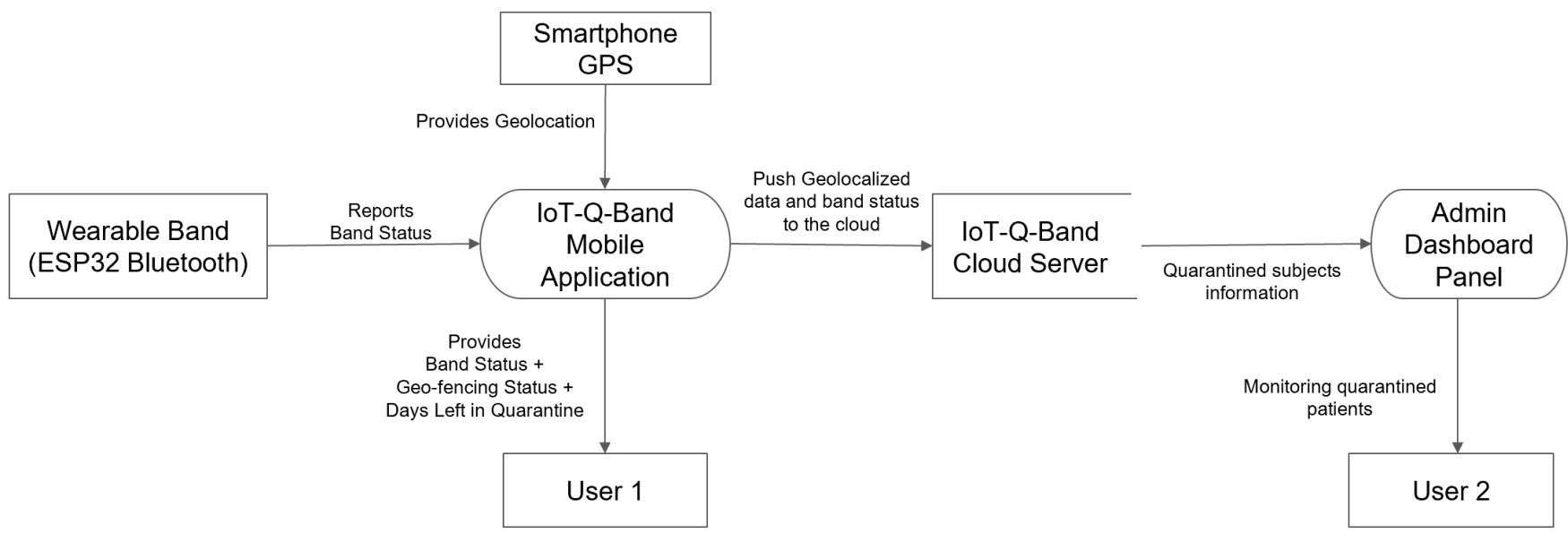

Figure 2. Data flow diagram of the IoT-Q-Band system. In this diagram, User 1 is a person wearing the IoT-Q-Band, and User 2 is a person/authority monitoring the quarantined subjects.

wearable band is meant only to be taken off when a pre-determined quarantine period is over. Concerned medical authorities have control of the tracking system and responsible for the initial subject registration, which reduces the privacy concerns of the quarantine subjects as well as ensures the legitimacy of the data. Using the global positioning satellite (GPS) based geofencing, the tracking system generates real-time alerts and allows the authorities to detect the absconding quarantine patients in real-time. The mobile app also reports about any disembarkation or tampering of the wearable band during an active quarantine. As the COVID-19 pandemic and associated lock-downs have disrupted the global supply chain [24] primarily of medical and electronics components, we have designed our prototype judiciously minimalist so that it requires fewer parts. Keeping in mind the WHO recommendation of a 14-day quarantine for a person who was exposed to a COVID-19 positive patient, we have selected the wearable band components and their mode of operation so that the included battery would be enough for the entire quarantine period. Since the reuse of the contaminated devices in epidemic scenarios are largely avoided, we also tried to keep the device cost low, so that the device could be incinerated after its use and still be mass-produced.

\section{System Overview}

Fig. 1 exhibits the IoT-Q-Band system's architecture. As the wearable band is powered up with a battery and should be lightweight for comfortable wear, we have taken care to make it with as few components as possible so that it can operate for a long time, and thus, we have re-used several of smartphone features, e.g., internet, and GPS access (like our previous work [25]).
The wearable band is worn by a quarantine subject either on the hand, arm, or leg and wirelessly connected to the mobile application via a Bluetooth link. The processing unit (ESP32 [26]) of the band repeatedly senses at specific time intervals whether the band has tampered. After sensing, the band transmits the status (a byte of data) to the mobile application at every 2 minutes interval. The subject will be registered to the IoT-Q-Band system only by concerned medical authority and responsible for setting the duration of the quarantine and authenticating the details. The supervisory role of authority automatically rules out the concern for malicious data entering the tracking system and also preserves the privacy of quarantine subjects. During the registration step, along with the personal details, the GPS coordinates of the quarantine location is also stored. The mobile application provides the following visual feedbacks: (1) whether the wearable band is working or tampered, (2) whether the subject is within the 50-meter radius (geo-fencing) of the registered quarantine location, and (3) the time left in the quarantine. After the initial subject's registration, the mobile application repeatedly pushes a JavaScript Object Notation (JSON) packet to the cloud server containing information about the wearable band's state (tampered or working), timestamp, and GPS coordinates (longitude and latitude) at regular intervals of 2 minutes.

A designated person can monitor each registered quarantine case via a web interface which fetches each active case and present in a readable form. The flow of the data starting from the wearable band until the monitoring web interface (admin dashboard panel) is portrayed in Fig. 2.

On the web interface, alerts are generated using onscreen visual highlights for the following cases: 


\section{(a) Inner Side of the Band}

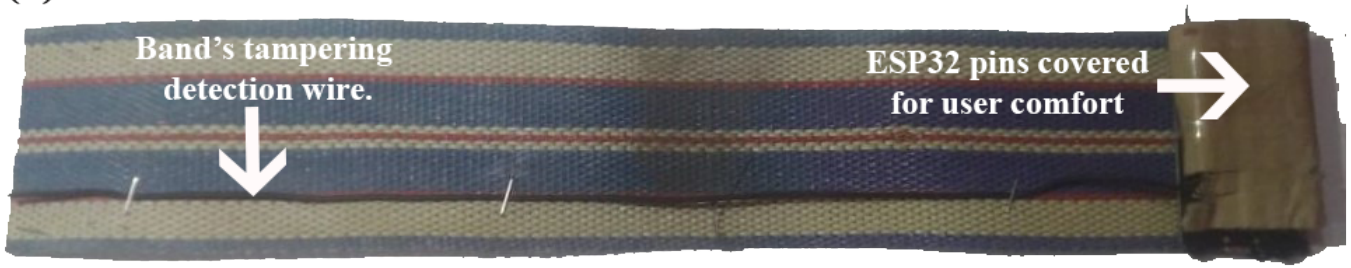

\section{(b) Outer Side of the Band}

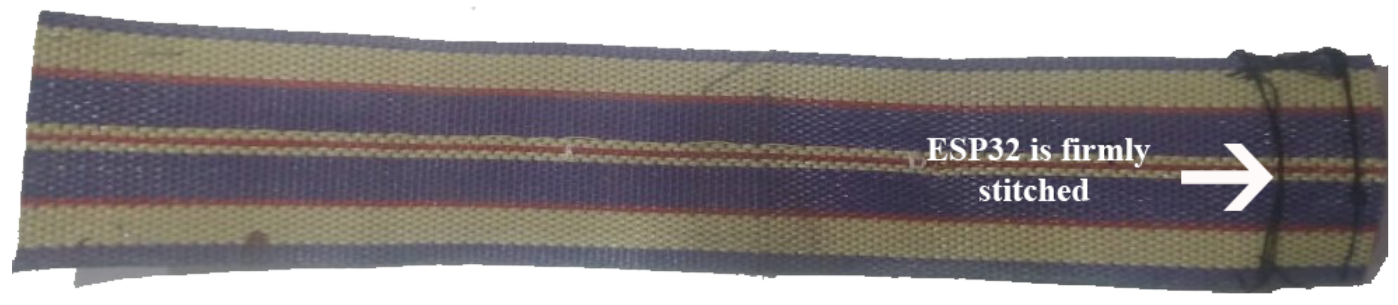

Figure 3. Construction detail of the loT-Q-Band wearable band showing its construction from (a) inner and (b) outer side.

- The wearable band is disembarked or tampered.

- The location of the patient is outside the Geofence (50 meters away from the registered quarantine location).

- The patient data is not updated in the last 10 minutes (calculated based on the timestamp of the last received packet).

Through the generated alert, if the concerned authority feels the quarantine subject has absconded, he can raise the alarm to the security agency, or otherwise, the status of the subject could be checked through a phone call for clarifications. Through the web interface, it is possible to know the last reported location of the patient.

\section{Components Used in the IoT-Q-Band}

In this section, we list out the components and their mode of operation, which makes the IoT-Q-Band.

- ESP32 [26]: It is a popular [27] [28], and widely studied [29] development kit, deployed in a variety of internet of things (IoT) applications. The compact form factor of the ESP32 (lengthwidth-thickness: 52 × 27 x 10mm) makes it suitable for use in a wearable device. In the IoT-Q-Band, ESP32 is responsible for sensing the wearable band's tampering and reporting this incident to the mobile application wirelessly through a Bluetooth link. Our wearable device keeps the connection alive with the mobile application and transmits wearable band status at specific time intervals. For this reason, the ESP32 operates in Modem Sleep mode, where CPU is always on, and the Bluetooth baseband and radio are disabled when not transmitting. To reduce the current consumption of IoT-Q-Band, we set the ESP32's CPU clock speed to $80 \mathrm{MHz}$ and set a low transmission duty cycle (1 byte in 2 minutes). In addition to this, we have disabled the ESP32's power light-emitting diode (LED) as well.

- Tampering detection wire: A conducting cable (20 centimeters in length) is connected between the ground pin and a general-purpose input/output (GPIO) pin of the ESP32 to detect any disembarkation or tampering of the wearable band.

- USB Cable: The ESP32 is powered up, using a male universal serial bus (USB) A to a male micro USB cable, 10 centimeters in length.

- Battery: Depending on the duration of the quarantine, as set by the authority, the battery capacity could be chosen. We have chosen a USB battery or power bank to power up the IoT-Q-Band.

- Clothing: The circuit is stitched over a cloth firmly over the hand, leg or arm.

Device Cost Analysis We have referred AliExpress (an online retail electronics store) for the analysis of device cost (accessed on April 21, 2020). We have considered the price for the first product whose rating is more than 4 with at least 1000 reviews.

- The ESP32 is available in the price range of \$3.6-5.

- The conducting cable (20 centimeters long) is available in the price range of \$0.02-0.05 per piece. 
(a)

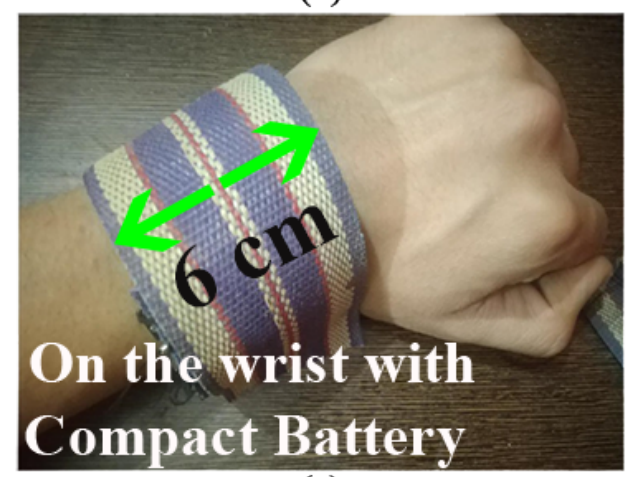

(c)

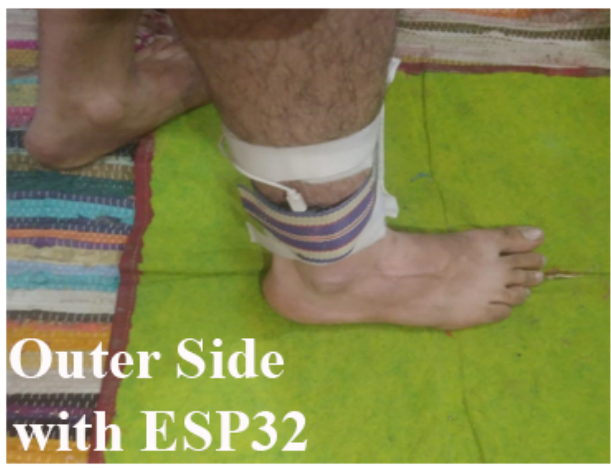

(e)

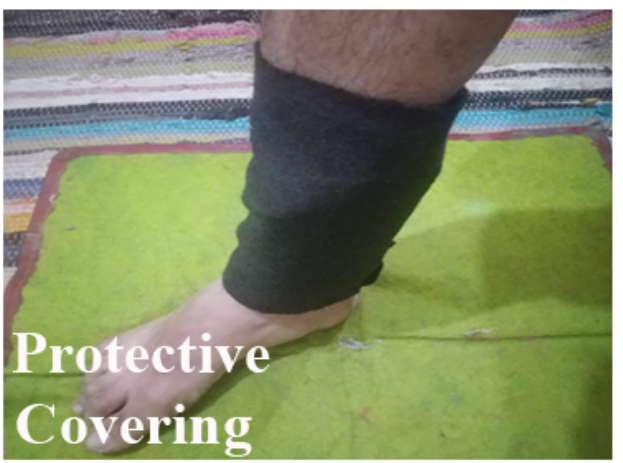

(b)

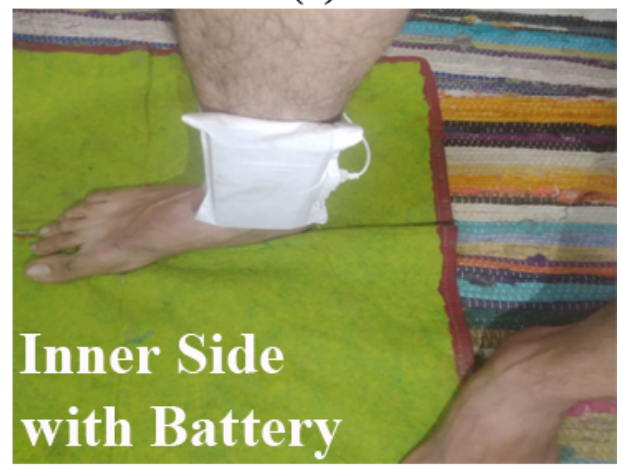

(d)

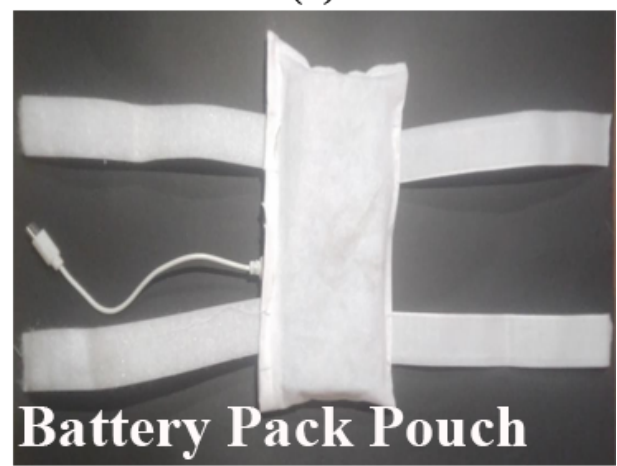

(f)

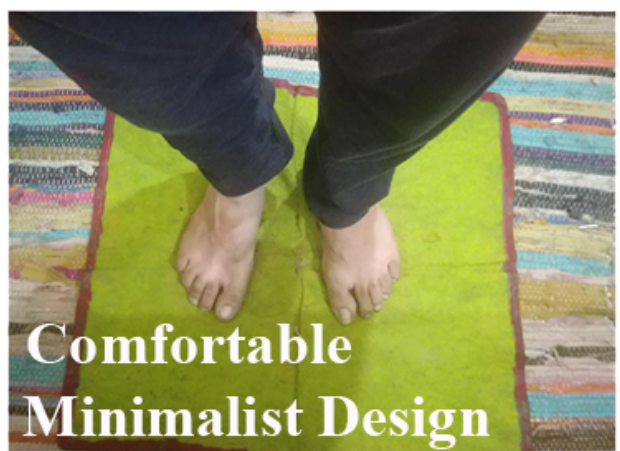

Figure 4. The IoT-Q-Band wearable is comfortably worn over the wrist or leg with firm fitting. (a) Depicts a user wearing the loT-Q-Band over the wrist. (b) and (c) shows the inner and outer side of the wearable when worn over the legs. (d) shows the battery pouch, whereas (e) shows the protective covering over the loT-Q-Band so that the band does not hinder the normal walking. ( $f$ ) shows that even a trouser could be easily worn over the loT-Q-Band.

- A 10 centimeters long USB cable is available at a price of $\$ 0.2$ per piece.

- A $10000 \mathrm{mAh}$ battery (power bank) is available in the price range of $\$ 8.5-12.8$, whereas a 20000 mAh battery lies in the price range of \$13.5-15. A compact battery is preferably chosen if the band is worn over the wrists.

Based on the above price data, the overall prototype cost with the $10000 \mathrm{mAh}$ battery lies in the range of $\$ 12.32$ 18.05 and with the 20000 mAh battery \$17.32-20.25.
Device Weight Analysis The IoT-Q-Band weighed around 30 grams without the battery. The ESP32 weighs 10 grams. The battery (10000 mAh), weighs around 260 grams.

\section{Implementation and Design Specifics}

Fig. 3 shows the IoT-Q-Band's construction from the front and back sides. The width of the fabric band over which the ESP32 is sewed is 6 centimeters. The ESP32 pins are covered so that a user is comfortable while wearing it. The tampering detection wire is soldered to a ground pin and sewed across the fabric. The other 
(a)

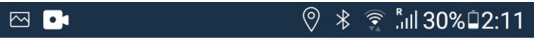

Quarantine Track Application

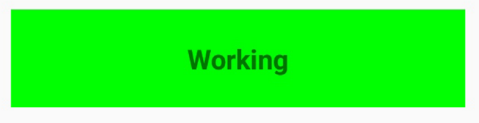

Home Location

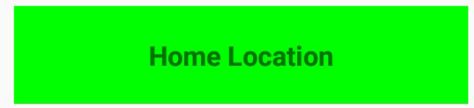

Quarantine days left : 14 (b)

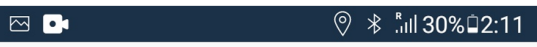

Quarantine Track Application
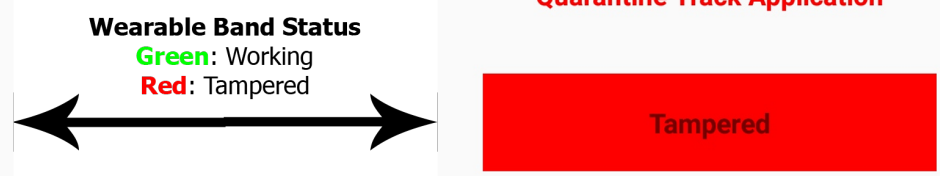

Patient Location Status

Green: Within 50m Geofence

Red: Outside 50m Geofence
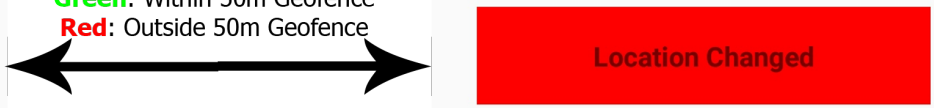

Days Left in Quarantine

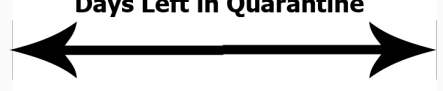

Quarantine days left : 14

Figure 5. The IoT-Q-Band system's mobile application screens showing the cases, (a) when the band is connected, and the subject is within 50 meters of registered quarantine Geo-location and (b) when the wearable tampered, and the patient is outside the 50 meters of the registered quarantine Geo-location. In each case, the user is shown the remaining quarantine duration.

end of the tampering detection wire is plug-n-play and connected to a digital input/output (DIO) pin, programmed as input (with the internal pull-up resistor enabled). The outer/front side of the IoT-Q-Band (Fig. 3.(b)) is relatively clean, where a few stitches are visible. The IoT-Q-Band is firmly and comfortably fitted to the wrist and legs using Velcro strips.

Fig. 4 shows the scenarios when the IoT-Q-Band is worn over the wrist and the leg. Fig. 4.(a) particularly shows the case when it is worn over the wrist. We recommend the IoT-Q-Band to be worn over the wrist only with a compact battery; otherwise, it would be uncomfortable for a subject to carry it over the whole quarantine period. Fig. 4.(b) and (c) shows the case when the IoT-Q-Band is worn over the right leg. We have kept the battery on the inner side of the legs so that the tampering detection wire connected to ESP32 is not accidentally disembarked while walking. Fig. 4.(d) shows the construction of the battery pouch. It could be seen that instead of single Velcro strip, it is supported by two Velcro strips due to relatively more weight (260 grams) than the IoT-Q-Band.

We recommend wrap-around protective clothing over the IoT-Q-Band and battery pack, as depicted in Fig. 4.(e). This protective clothing prevents unnecessary friction with the band's components while walking. Ultimately Fig. 4.(f) shows that the IoT-Q-Band could be worn comfortably even with regular clothing.

Fig. 5 shows the IoT-Q-Band system's mobile application screens, which has three visual indicators. If the IoT-Q-Band has tampered with, the leading indicator changes its color from green to red and concurrently transmits the same information to the cloud server. This application also performs the geofencing task, and the middle indicator changes its color from green to red when a quarantine subject is 50 meters away from the stored quarantine location (during the initial registration); the same location status change is pushed to the cloud server as well. The third indicator indicates the days left in the quarantine. Fig. 6 shows the IoT-Q-Band system monitoring web interface where the data is displayed in a tabular format, and accessible only to a designated authority. This web interface enables centralized monitoring, and make it convenient to track several quarantine subjects together. The interface generates a visual alert (highlight the text with red font) whenever a person is outside his geo-fence, or if the band has been tampered. 
All Patients Data

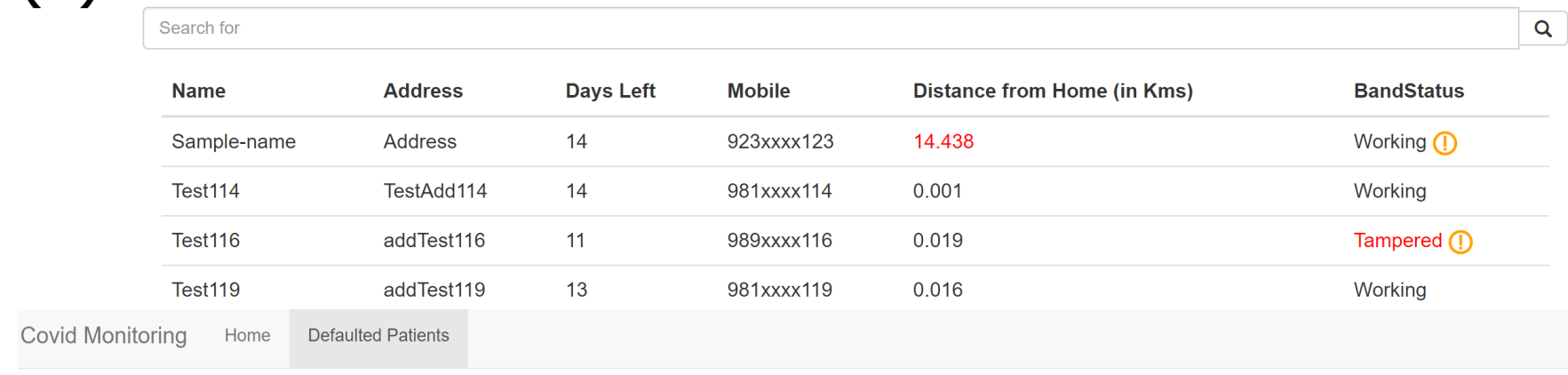

(b)

Defaulted Patients Data

\begin{tabular}{lllllll}
\hline Search for & & & & & Q \\
\hline Name & Address & Days Left & Mobile & Distance from Home (in Kms) & BandStatus \\
\hline Sample-name & Address & 14 & $923 x x x \times 123$ & 14.438 & Working (1) \\
\hline Test116 & addTest116 & 11 & $989 x x x \times 116$ & 0.019 & Tampered (1)
\end{tabular}

Figure 6. The IoT-Q-Band system's monitoring web interface (a) displays the screen with all the test subject details, and (b) displays the screen with only possible defaulted subject details.

An exclamation mark is shown when the server haven't received data from last 10 minutes. We have provided a separate page titled "Defaulted Patients" showing only the flagged cases, which makes it easier to look out for the suspected cases.

\section{Experimental Validation and Results}

Current Consumption Analysis of the IoT-Q-Band When the IoT-Q-Band is not transmitting, the current consumption is about $30 \mathrm{~mA}$, and while transmitting over the Bluetooth, it consumes $100 \mathrm{~mA}$ of current (measured through a high-resolution multi-meter). Also, we found that while transmitting 1 byte of data, the current consumption stays at $100 \mathrm{~mA}$ for 8 seconds (we realize that it is the time taken for the ESP32 to wake up the radio, transmit the data and then turn off the radio after being idle for a while in the modem sleep mode). Since we have decided to transmit a byte every 2 minutes, the IoT-Q-Band consumes $30 \mathrm{~mA}$ for 112 seconds and $100 \mathrm{~mA}$ for the next 8 seconds, and thus, the average current consumption by the band comes to be $34.66 \mathrm{~mA}$. Thus we calculate that with a $10000 \mathrm{mAh}$ battery pack, the band can operate almost 12 days and with a $20000 \mathrm{mAh}$ battery pack for almost 24 days.

GPS Location Uncertainty Experimentally we found that the GPS location uncertainty reported through a smartphone generally depends on the surroundings or the measurement environment. Over 50 independent observations (with varying environmental conditions), we found the error in measurements lie between $\pm(5$ 15) meter.

Prototype's Validation with Test Subjects We have created four independent test subjects (4 set of IoTQ-Bands and mobile phones) namely, "Sample-name", "Test114", "Test116" and "Test119". The cloud-based monitoring system generates alerts for the user named "Sample-name" when the distance from the quarantine is greater than > 50 meter. "Test114" and "Test119" are kept within the 50-meter radius with the band working, and thus the system doesn't throw any alert. The "Test116" is kept inside the 50-meter radius of registered quarantine location, but with the band broken, the system successfully shows this status as well.

\section{Conclusion}

The IoT-Q-Band presents a minimalist design, keeping in mind the cost, global supply chain disruption, and the WHO's recommended average quarantine period in mind. The IoT-Q-Band, with the bundled mobile application and cloud-based monitoring system, provides a scalable, low-cost solution to detect the absconding COVID-19 quarantine subjects and track them in real-time. The components of the wearable band, their mode of operation, and the battery are chosen such that they stay operational throughout 
the quarantine period, also validated via the current consumption analysis. Due to the possibility of contamination, the reuse of IoT-Q-Band could be avoided; thus, the cost of this prototype is kept less by reusing several smartphone's features. As an economical solution, the IoT-Q-Band could benefit lowincome areas of the world where it could be used to keep track of quarantine subjects.

\section{Future Work}

The prototype's conceptualization and development were done, keeping a lockdown situation in mind, through remote collaborations. India went to a complete lockdown on 24th March 2020 till 14th April 2020 (which is further extended till 3rd May 2020), which seriously hindered the supply of components and movements all across the nation. Thus, the current state of the prototype opens multiple new opportunities for researchers. One of the precise directions would be to predict the probability of a person to abscond a quarantine using biosensor data fitted over the IoT-QBand and machine learning. Device power optimization and adequate battery research is also a direction to follow. Last but not least, for making the wearable comfortable enough to be worn over arms and legs, we have used the clothing as a possible skeleton for the device, which could be alternatively $3 \mathrm{D}$ printed with a variety of materials.

Acknowledgement. Authors are thankful to the developers of the technologies that make a remote collaboration possible and the technical team of CircuitUncle.com especially Mr. Punit for his invaluable contribution to this project. Authors firmly believe in the use of wearable devices, on humanitarian grounds only. Any privacy violation of an individual using a wearable device is unethical and strongly condemned.

\section{References}

[1] The World Health Organization (2014) What is a pandemic? Emergencies preparedness, response, (WHO) [Online] (accessed on April 21, 2020).

[2] Kelly H. (2011) The classical definition of a pandemic is not elusive. Bulletin of the World Health Organization, (WHO) 89(7): 540-541.

[3] The World Health Organization (2020) WHO DirectorGeneral's opening remarks at the media briefing on COVID-19 - 11 March 2020 Speeches, (WHO) [Online] (accessed on April 21, 2020).

[4] The World Health Organization (2020) Rolling updates on coronavirus disease (COVID-19) Coronavirus disease 2019/Events as they happen, (WHO) [0nline] (accessed on April 21, 2020).

[5] The World Health Organization (2020) Coronavirus disease (COVID-19) Pandemic Coronavirus disease 2019, (WHO) [Online] (accessed on April 21, 2020).

[6] Liu .T, et al. (2020) Transmission dynamics of 2019 novel coronavirus (2019-nCoV). bioRxiv. 2020;
DOI:10.1101/2020.01.25.919787 (preprint) (accessed on April 21, 2020).

[7] Zhao, S., et al. (2020) Preliminary estimation of the basic reproduction number of novel coronavirus (2019-nCoV) in China, from 2019 to 2020: A data-driven analysis in the early phase of the outbreak. International Journal of Infectious Diseases, (ELSEVIER) 92: 214-217.

[8] Majumder, M. and Mandl, K. (2020) Early Transmissibility Assessment of a Novel Coronavirus in Wuhan, China. (SSRN): 1-7.

[9] Wilder-Smith, A. and Freedman, D.O. (2020) Isolation, quarantine, social distancing and community containment: pivotal role for old-style public health measures in the novel coronavirus (2019-nCoV) outbreak. Journal of Travel Medicine, (OUP) 27(2): 1-4.

[10] The World Health Organization (2020) Considerations for quarantine of individuals in the context of containment for coronavirus disease (COVID-19). Technical documentation, Interim guidance, (WHO): 1-4 [0nline] (accessed on April 21, 2020).

[11] DiGiovanni, C., Conley, J., Chiu, D. and Zaborski, J. (2004) Factors influencing compliance with quarantine in Toronto during the 2003 SARS outbreak. Biosecurity and bioterrorism: biodefense strategy, practice, and science, (MAL) 2(4): 265-272.

[12] Caruso, G. D. (2016) Free will skepticism and criminal behavior: A public health-quarantine model. Southwest Philosophy Review, (SSRN) 32(1): 25-48.

[13] Deekshith, M. (2020) Covidiots everywhere; cases of foreign returnees flouting home quarantine in rise. Nation, Current Affairs, Deccan Chronicle [Online] (accessed on April 21, 2020).

[14] Breakfast, S. (2020) KwaZulu-Natal COVID-19 patient charged after absconding quarantine. News, The South African [Online] (accessed on April 21, 2020).

[15] Fitzsimmons, C. (2020) They haven't listened: Medical professionals skipped quarantine and flew interstate. News, The Sydney Morning Herald [Online] (accessed on April 21, 2020).

[16] Mu-chun, S. and Kao, E. (2020) 6 suspected Vietnamese stowaways escape from quarantine. Society, Focus Taiwan [Online] (accessed on April 21, 2020).

[17] Boillat, T., Rivas, H. and Wac, K. (2018) "Healthcare on a Wrist": Increasing Compliance Through Checklists on Wearables in Obesity (Self-)Management Programs. Digital Health. Health Informatics, (Springer): 65-81.

[18] Brannon, E., Cushing, C., Crick, C. and Mitchell, T. (2016) The promise of wearable sensors and ecological momentary assessment measures for dynamical systems modeling in adolescents: a feasibility and acceptability study. Translational Behavioral Medicine, (OUP), 6(4): 558-565.

[19] Loos, J.R. and Davidson, E.J. (2016) Wearable health monitors and physician-patient communication: the physician's perspective. In Proceedings of 2016 49th Hawaii International Conference on System Sciences (HICSS), (IEEE): 3389-3399.

[20] Sung, M., Marci, C. and Pentland, A. (2005) Wearable feedback systems for rehabilitation. Journal of NeuroEngineering and Rehabilitation, (Springer), 2(17): 1-12. 
[21] Indiatimes (2020) Coronavirus suspects under home quarantine to have their left hand stamped in Maharashtra. News, The Economic Times [Online] (accessed on April 21, 2020).

[22] Mahale, A. (2020) Coronavirus | Western Railway deboards 17 passengers bearing home quarantine stamp. News, The Hindu [Online] (accessed on April 21, 2020).

[23] Pandey, A. (2020) Coronavirus in India: Man stamped for quarantine in Mumbai caught at Secundarabad railway station. News, India Today [0nl ine] (accessed on April 21, 2020).

[24] Ivanov, D. (2020) Predicting the impacts of epidemic outbreaks on global supply chains: A simulation-based analysis on the coronavirus outbreak (COVID-19/SARSCoV-2) case. Transportation Research Part E: Logistics and Transportation Review, (ELSEVIER) 136: 1-14.

[25] Singh, V.K., Chandna, H. and Upadhyay, N. (2019) SmartPPM: An Internet of Things Based Smart Helmet
Design for Potholes and Air Pollution Monitoring. EAI Endorsed Transactions on Internet of Things, (EAI) 5(18): 1-9.

[26] Espressif Systems (2020) ESP32 Series Datasheet. Datasheet, [0nline] (accessed on April 21, 2020).

[27] Aghenta, L. O. and Iqbal, M. T. (2019) Low-Cost, Open Source IoT-Based SCADA System Design Using Thinger. IO and ESP32 Thing. Electronics, (MDPI) 8(8): 1-24.

[28] Sarjerao, B. S. and Prakasarao, A. (2018) A Low Cost Smart Pollution Measurement System Using REST API and ESP32. In Proceedings of 2018 3rd International Conference for Convergence in Technology (I2CT), (IEEE) $: 1-5$.

[29] Maier, A., Sharp, A. and Vagapov, Y. (2017) Comparative analysis and practical implementation of the ESP32 microcontroller module for the internet of things. In Proceedings of 2017 Internet Technologies and Applications (ITA) (IEEE) :143-148. 